$(32.8 \%)$ FSW. The self-reported mean number of sexual partners in the past 4 weeks was 125 (range 8-440) translating to 33,496 sex acts/month overall. HIV prevalence was $76.0 \%$. Infectious hepatitis B was present in $13(4.9 \%)$ and treponemal antibodies were detected in 54(20.1\%). Most (73.7\%) of 196 FSW tested had evidence of one or more genital tract infection with: BV 173 (88.3\%), MG 57 (29.1\%), NG 28 (14.3\%), TV 23 (11.7\%) and CT $16(8.2 \%)$. Only 49 (25\%) FSW with laboratory-confirmed infections would qualify for syndromic management. All 21 cultured gonococci were susceptible to cephalosporins.

Conclusion There is a high prevalence of HIV and STIs among those FSW tested. The majority of STIs are asymptomatic.

Disclosure of interest statement The study was funded by USAID/PEPFAR and AIDS Fonds. SD bioline tests were provided by SD diagnostics.

\section{P14.18 UNDERSTANDING THE INTENTION TO UNDERGO REGULAR HIV TESTING AMONG FEMALE SEX WORKERS IN BENIN: A KEY ISSUE FOR ENTRY INTO HIV CARE}

\begin{abstract}
1,2Batona Georges* ${ }^{1,2}$ Gagnon Marie-Pierre, 'Simonyan David, 1,3Guedou Fernand Aimé, ${ }^{1,4,5}$ Alary Michel. ${ }^{1}$ Research Centre of the Centre Hospitalier Universitaire de Québec, Quebec City, Quebec, Canada; ${ }^{2}$ Faculty of Nursing, Université Laval, Quebec City, Quebec, Canada; ${ }^{3}$ Dispensaire IST, Cotonou, Bénin; ${ }^{4}$ Department of Social and Preventive Medicine, Université Laval, Quebec City, Quebec, Canada; ${ }^{5}$ Institut National de Santé Publique Du Québec, Quebec City, Quebec, Canada
\end{abstract}

10.1136/sextrans-2015-052270.530

Background HIV testing constitutes an entry point for HIV prevention and access to care. Although access to tests has increased in most low- and middle-income countries in recent years, regular HIV testing among high-risk populations remains a challenge. Understanding the determinants of regular HIV testing is the key to improving treatment-as-prevention programs and access to care. This study aimed to identify psychosocial factors associated with the intention to be HIV tested every 3 months among female sex workers (FSWs) in Benin.

Methods We developed an interview questionnaire based on the Theory of Planned Behaviour and other theoretical variables. We interviewed 450 FSWs in their work place. Using Amos software, we applied structural equation modelling to identify the determinants of intention.

Results Previous testing was reported by $87 \%$ of FSWs, $40 \%$ of whom reported having been tested in the last 3 months. More than half of the FSWs (69\%) showed a strong intention to be HIV tested during the next 3 months. The structural model indicates that $55 \%$ of the variance in intention is explained in descending order of importance (standardised coefficient weight, b) by perceived control $(\beta=0.26, \mathrm{P}<0.001)$; descriptive norms $(\beta=0.24, \mathrm{P}<0.001)$; control beliefs $(\beta=0.22, \mathrm{P}<$ $0.001)$; habits $(\beta=0.20, \mathrm{P}<0.001)$; attitude $(\beta=0.12, \mathrm{P}=$ $0.01)$; Perceived risk $(\beta=0.07, \mathrm{P}=0.03)$; and normative beliefs $(\beta=20.07, \mathrm{P}=0.03)$.

Conclusions This is the first theoretically based study identifying determinants of intention to undergo regular HIV testing among FSWs in sub-Saharan Africa. The results can inform development of interventions to maintain and increase regular HIV testing among FSWs, thus reinforcing primary prevention and supporting early access to care.

The authors have no conflicts of interest to disclose. This study was funded by the Canadian Institutes of Health Research (Grant no. ROH-115205).

\section{P14.19 THE IMPACT OF SEX WORK ON WOMEN'S PERSONAL ROMANTIC RELATIONSHIPS}

${ }^{1} \mathrm{C}$ Bellhouse ${ }^{*},{ }^{2,3} \mathrm{~S}$ Crebbin, ${ }^{1,4} \mathrm{C}$ Fairley, ${ }^{4} \mathrm{~B}$ Bilardi. ${ }^{1}$ Melbourne Sexual Health Centre, Alfred Health, Melbourne, Australia; ${ }^{2}$ The University of Melbourne; ${ }^{3}$ Nexus Primary Health; ${ }^{4}$ CentralClinical School, Monash University, Melbourne, Australia

\subsection{6/sextrans-2015-052270.531}

Introduction Female sex workers are a diverse group of women who have previously been studied extensively in relation to prior rates of abuse, drug and alcohol use, mental and physical health and condom use. Very limited research has been done regarding sex workers' personal romantic relationships outside of work and the impact the nature of their work has on their relationships. The aim of this study was to explore the impact sex work has on personal romantic relationships and the experiences women have balancing their work and personal lives.

Methods Fifty-five Melbourne based indoor sex workers completed a self-report questionnaire about their work, personal relationships, condom use and rates of physical and sexual abuse. Following analysis of the questionnaire findings, a further six sex workers were independently interviewed face to face to 'member check' the findings and determine if the broader findings were representative of their experience.

Results For the majority of women, sex work was found to negatively impact their personal romantic relationships. The main ways sex work negatively impacted on their personal relationships included problems stemming from lying, trust, guilt and jealousy as well as stigma in the wider community. It was common for women to use various means to mentally separate their work and home lives as a coping mechanism. A small number of women reported sex work had a positive impact on their relationships, which they mainly attributed to their partners positive attitude toward their work.

Conclusion The findings of this study suggest that further larger scale research is required to explore the impact of sex work on romantic relationships, the coping mechanisms women use to manage the tensions between sex work and their romantic relationships, and the ways in which negative impacts could be minimised for women in this diverse group.

Disclosure of interest statement No conflict of interest.

\section{P14.20 RELATIONSHIP MYTH BETWEEN SEX WORKERS, STI'S AND HIV}

${ }^{1} \mathrm{Q}$ Joe, ${ }^{2} \mathrm{~A}$ Dee ${ }^{*}$. Respect Inc

10.1136/sextrans-2015-052270.532

Introduction For years Sex Workers in Australia, especially QLD, have been incorrectly attributed to the increase of STI's and HIV in the general community. This article will conclude that Sex Workers are not the cause of transmission increase in STI's and HIV. To the contrary Sex Workers have very low levels of STI's and HIV. Furthermore Sex Workers have helped to educated clients to reduce transmission of STI's and HIV. This article demonstrates the important role of Respect Inc in health promotion of Sex Workers with provision in education of STI's and HIV, so Sex Workers can keep themselves safe whilst doing Sex Work.

Methods The team will use a number of methods to collect data, all methods are traditional and dependent on targets. For example, we have used paper questionnaires to collect information from Sex Workers, this reduced barriers when asking Sex 
Workers personal questions. We conducted face to face interviews with some of the Sex Worker friendly GPs (General Practitioners) who provide sexual health certificates to Sex Workers. We have conducted telephone interviews with Sex Workers who do FIFO (fly in fly out) to regional mining towns in QLD. We collated this data with data provided by Respect Inc.

Results After collection of data we formatted charts and graphs. We found levels of STI's and HIV among Sex Workers were relatively low. GPs confirmed, Sex Workers are informed about STI's and HIV. Respect Inc provided data with hundreds of Sex Workers accessing offices across Qld for Safe Sex, STI's and HIV information, with positive sexual health outcomes.

Conclusion Sex Workers in Australia (QLD) have relatively low levels of STI's and HIV. Sex Workers are not the cause of increasing transmissions of STI's and HIV. Sex Workers often face stigma and discrimination in the wider community. Please respect Sex Work as a career of choice.

SEX WORK IS REAL WORK

\section{P14.21 THE IMPACT OF THE IEC (INFORMATION, EDUCATION AND COMMUNICATION) IN THE AFFIDAVIT OF SEX WORKERS}

Floribert Monga Lisangi*. Study Realized by the Youth Center Coulibaly Sidiki of the University of Kinshasa (Democratic Republic of Congo)

\subsection{6/sextrans-2015-052270.533}

Background Sex workers (sw) constitute a very important group in the transmission of HIV infection. Their sanitary and social follow-up has an impact in the prevention of HIV infection. Among strategies implemented at the youth centre Coulibaly sidiki of university of Kinshasa, the IEC occupies a very important place. We have realised a study in order to determine the impact of the IEC in the affidavit and prevention of STI and HIV next to sex workers.

Methods It's about prospective, descriptive study realised at the youth centre Coulibaly sidiki of the University of Kinshasa on a period of 3 months (September to November 2012).

We have included Sex Workers enrolled to socio-sanitary file of the centre, who came to make their medical visit during the period of study and who accepted to participate to the study.

They have been questioned through mid-directive questions sheet, oriented for the following data: socio-demographic data, questions concerning the sanitary follow-up, on going of IEC sessions, the impact of IEC sessions, in end some open question was devoted to possibility suggestions of SW to increase their follow-up.

Result Fifty two Sex workers were included. The mean age was 35 years. Among all of them 99\% was Christians. The majority of SW was living at Kinshasa (75\%). 62\% were divorced; $24 \%$ single; 6, 5\% widows. Among SW: 16 or $40 \%$ had minor children. More than the half of SW did not have an other professional activity and their intellectual level was low. During the IEC sessions $87 \%$ of SW were choosing themselves the themes to discuss: STI and HIV/AIDS (26\%), police harassment (12, 5\%); the solidarity between SW (16\%). The frequency of STI was $65,7 \%$ before the IEC sessions and $68 \%$ of SW ignored the type of STI. Systematic using of condom was 78,5\%. Concerning evaluation of their knowledge in the field of fighting against HIV and STI, acquired through IEC session: 30\% knew the HIV transmission's way, $14,5 \%$ recognised easily a STI.
Suggestions reached out by Sex Workers was to sustain session of IEC $37,5 \%$; diversify themes $15 \%$; changing schedule of IEC $12,5 \%$. A reconversion in others professional's activities and a funding of activity that generates profit (AGP) was the mains preoccupations of Sex Workers.

Conclusion Sex workers occupied an important place in the HIV and STI propagation because they constitute a gangway with the general population. The IEC is still to increase to acquire the best strategies of HIV and STI infection's prevention.

\section{P14.22 TO PREVENT HIVIAIDS THROUGH AWARENESS RAISING AND SOCIAL BEHAVIOURS CHANGE OF SEX WORKER IN BANGLADESH - AN EXPERIENCE FROM KANDAPARA BROTHEL, TANGAIL, BANGLADESH}

Tapas Kumar Saha*, Nari Mukti Sangha. Sabalia (Panjapara), Tangail-1900, Bangladesh

10.1136/sextrans-2015-052270.534

Issues Nari mukti Sangha (NMS) is a Self Help Group (SHG). We can awareness build up of SWs by (i) One-to-One Session (ii) Group discussion (iii) Peer education training (iv) HIV Test by ICDDRB Bangladesh (v) STI Clinic and (vi) Support services. Description NMS is a social service organisation, Government Registration no. TA-1333/2000. It is purely non-political and solely sex workers' organisation. Its aim is to establish the social, legal and human rights in the society and also women empowerment. We are directly involved to reduce STD/HIV/AIDS through awareness development and other intensive support services like STD clinic inside and outside of the brothel. Now we are working in trafficking field in Bangladesh. Before working in the field we do base line survey and post survey.

Lesson learned After completion the work the result one is SWs can encourage to use condom for protecting HIV/AIDS to the client. Another one is to establish the social and human rights in the society.

Conclusion SWs will develop capacity which will carry out the important benefit to prevent the HIV/AIDS program of our organisation. Nari Mukti Sangha is a fully committed to work with HIV/AIDS.

\section{P14.23 TRANSGENDER SEX WORKERS RESPONSE TO HIV IN PAPUA NEW GUINEA}

Obert Samba*. Save the Children in Papua New Guinea

\subsection{6/sextrans-2015-052270.535}

Introduction Save the Children SRH Poro Sapot Project is a national STI and HIV prevention project. The project represent the voice, health and interests of sex workers, MSM and Transgender people in Papua New Guinea at international and national levels so that they voice and health must be heard and their issues be considered.

Transgender women in Papua New Guinea, most of who were rejected by their own families are now on the streets doing sex work to survive. Sex work is illegal and most often they are faced with stigma and discrimination and violence. Over the years sex worker trannies have been infected and cannot access the health facilities because of our sexuality and therefore end up dying. The strong religious and cultural beliefs makes it hard for transgender sex workers to live a normal life. 